\title{
LOIASIS. APROXIMACIÓN A UNA FORMA DE PARASITOSIS OCULAR
}

\section{LOIASIS. APPROACH TO A FORM OF OCULAR PARASITOSIS}

\author{
LÓPEZ-RODRÍGUEZ I ${ }^{1}$, DE-LA-FUENTE-CID R ${ }^{1}$, CARNERO-LÓPEZ JM ${ }^{1}$, \\ CORDIDO-CARBALLIDO $\mathrm{M}^{2}$, ZÚÑIGA-RODRÍGUEZ $\mathrm{C}^{3}$
}

\begin{abstract}
RESUMEN
Caso clínico: Presentamos el caso de un camerunés que refiere la presencia de un gusano en ambos ojos de forma intermitente desde hace 5 años. El examen biomicroscópico reveló la existencia de un gusano reptante subconjuntival. El análisis microbiológico tras su extracción quirúrgica confirmó que se trataba de una forma adulta de Loa-Loa.

Discusión: La loiasis es una enfermedad parasitaria endémica en África. El reconocimiento de la enfermedad tiene interés debido al incremento de la emigración africana hacia España.
\end{abstract}

Palabras clave: Loa-Loa, Loiasis, parasitosis ocular.

\section{INTRODUCCIÓN}

La loiasis es una filariosis hasta ahora restringida a los países africanos. El aumento de los movimientos migratorios hacia otros países como España representa una posibilidad creciente de que la enfermedad se detecte fuera de las regiones en que es endémica.

Se presenta un caso de Loiasis ocular con identificación directa del gusano que permitió la confirmación de la enfermedad.

\begin{abstract}
Case report: We present the case of a man from Cameroon who was referred because of the presence of a worm in both eyes, intermittently, over a five-year period. Slit-lamp examination revealed a creeping worm under the conjunctiva. Its surgical removal enabled microbiologic confirmation of a mature form of Loa-Loa.

Discussion: Loiasis is a parasitic disease endemic in Africa. Because of the increase of African emigration to Spain, the possibility of this condition must be considered in Spain (Arch Soc Esp Oftalmol 2007; 82: 55-58).
\end{abstract}

Key words: Loa-Loa, Loiasis, ocular parasitosis.

Recibido: 1/6/05. Aceptado: 20/12/06

Hospital Juan Canalejo. La Coruña. España.

1 Licenciado en Medicina.

2 Doctor en Medicina.

3 Licenciada en Farmacia.

Correspondencia:

I. López Rodríguez

C/. San Ignacio, $1,4{ }^{\circ} \mathrm{C}$

15001 La Coruña

España

E-mail: iloprod@yahoo.es 
El examen del polo anterior demuestra la existencia de una estructura acordonada, móvil que se desplaza reptante bajo la conjuntiva bulbar superior de su ojo derecho (fig. 1). Ante los hallazgos se procede a la extracción quirúrgica bajo anestesia local de un gusano integro de $5 \mathrm{~cm}$ de longitud (fig. 2).

El estudio microbiológico confirma el diagnóstico de Loa Loa en su forma adulta (hembra).

\section{DISCUSIÓN}

La loiasis es una enfermedad parasitaria endémica en zonas del oeste y centro de África (Nigeria, Camerún, Congo), se estima que el número de individuos afectados oscila entre 3 y 13 millones, y que aproximadamente, el 30\% de los visitantes de larga estancia quedan parasitados por este organismo.

Loa-Loa, también conocido como gusano ocular africano (african eyeworm) es un nematodo filarial propio de la especie humana de cuerpo delgado, los machos miden 2-4 cm de largo por 0,3-0,4 $\mathrm{mm}$ de y las hembras $5-7 \mathrm{~cm}$ por $0,5 \mathrm{~mm}$.

El ciclo vital biológico requiere el concurso de un artrópodo vector; las hembras del género Chrysops (mosca mango). La mosca pica al hombre contaminado e ingiere sangre conteniendo microfilarias, en la mosca la microfilaria desarrolla varios estadíos hasta pasar al de larva infecciosa a los 10-12 días, la cual es transmitida a los humanos por su picadura. Desde la piel las larvas emigran al tejido celular

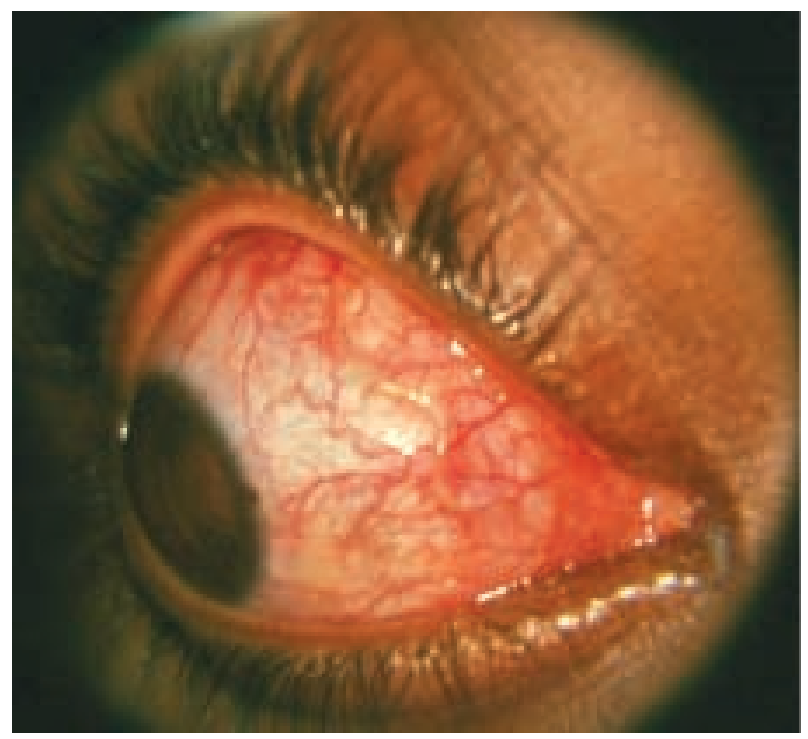

Fig. 1: Loa-Loa subconjuntival. subcutáneo donde al cabo de 3 meses se transforman en individuos adultos. El apareamiento se realiza en la piel desde donde las hembras grávidas emiten microfilarias a sangre periférica, a los 6-12 meses de la parasitación durante el período diurno con un pico al mediodía (1).

Tras un período de incubación de unos tres meses, aparecen las manifestaciones clásicas, habitualmente bien toleradas, consecuencia de la migración subcutánea de los vermes adultos y de fenómenos inmunoalérgicos:

- Prurito: se localiza en extremidades superiores, tórax, espalda y cara.

- Reptación subcutánea de los adultos: aparece un hormigueo desagradable, o picor mientras un cordón serpenteante se desplaza bajo la piel a razón de un centímetro por minuto. La migración subconjuntival es patognomónica para Loa-Loa y da lugar a sensación de cuerpo extraño, inyección conjuntival, lagrimeo y edema palpebral y conjuntival.

- Edemas de Calabar: es el signo más común aunque no patognomónico ya que pueden aparecer en otras filariosis. Se caracteriza por la aparición en las extremidades (muñecas, tobillos) o cara de dolor, prurito o urticaria y unas horas más tarde de un angioedema migratorio y transitorio de 1-3 días de duración.

Tardíamente pueden aparecer complicaciones como: afectación renal (nefritis intersticial), cardíaca (insuficiencia cardíaca derecha) o neurológica (meningoencefalitis); asociadas a fenómenos de hipersensibilidad o a pacientes con microfilaremia elevada (2).

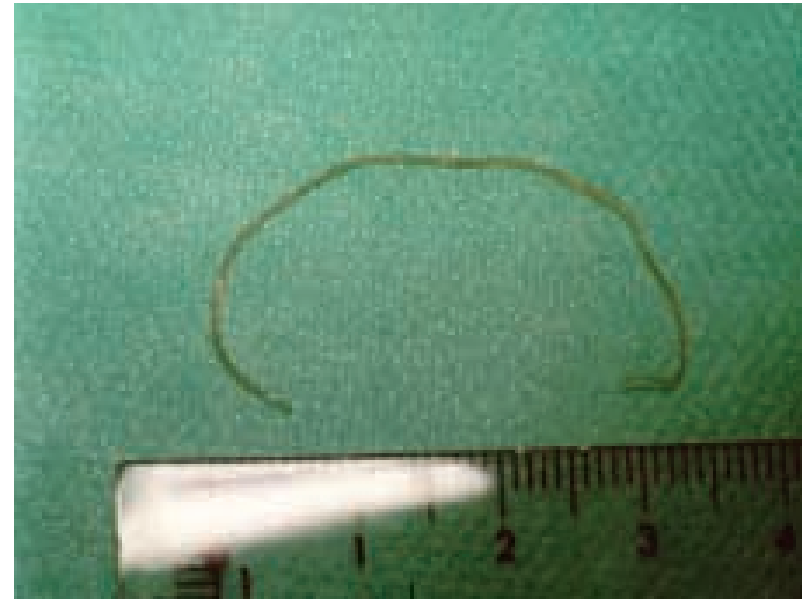

Fig. 2: Loa-Loa hembra en su forma adulta tras la extracción subconjuntival. 
Debido al aumento de viajeros a zonas de alta endemicidad y al gran incremento de emigrantes procedentes de ellas en nuestro país, entendemos que el conocimiento de esta patología y el estar alerta en pacientes de riesgo previene la morbilidad asociada a la loiasis ocular. La enfermedad una vez reconocida, tiene un tratamiento sencillo y eficaz.

El diagnóstico fundamentalmente clínico; debe sospecharse en pacientes procedentes del área de endemia que presenten síntomas sugestivos de loiasis (3). Aunque en casos, como el que se presenta, la migración subcutánea o subconjuntival de los adultos permiten el diagnóstico de certeza con la identificación del gusano tras su extracción quirúrgica. En la mayoría, el diagnóstico se establece mediante observación microscópica de las microfilarias en fresco, o tras la tinción de preparaciones hemáticas, junto con la valoración de los hallazgos analíticos complementarios (eosinofilia, PCR, IgE cuantificada).

La extracción quirúrgica completa del gusano tras anestesia tópica o subconjuntival, (a veces paralizándolo con cocaína al 4\%), es simple y efectiva. Se han descrito casos de inmovilización del gusano con criodo y extracción posterior (4).

El fármaco de elección es la dietilcarbamazina (DEC), eficaz contra las formas adultas y microfilarias, requiriendo la administración de varios ciclos. El tratamiento no está exento de efectos indeseables como reagudización de los síntomas y complicaciones renales o encefálicas, especialmente en pacientes con microfilaremia elevada. En estos casos, se debe comenzar con dosis bajas para ir aumentando progresivamente y asociar antihistamínicos y corticoides los primeros 4 días (pauta de tratamiento con
DEC: día 1: $1 \mathrm{mg} / \mathrm{kg}$ en una dosis; día 2: $2 \mathrm{mg} / \mathrm{kg}$ en dos dosis; día 3: $4 \mathrm{mg} / \mathrm{kg}$ en dos dosis; día 4-21: 6$9 \mathrm{mg} / \mathrm{kg}$ en 3 dosis).

Otros fármacos utilizados son la ivermectina, con una dosis única de $150 \mathrm{ug} / \mathrm{kg}$ para reducir la microfilaremia en casos donde la DEC puede tener efectos secundarios adversos, y el mebendazol y albendazol (5).

Dado que el humano es el único reservorio conocido para Loa-Loa y que la infección es transmitida por la mosca mango es aconsejable realizar quimioprofilaxis para los residentes temporales en zonas endémicas con DEC oral a dosis única semanal de $300 \mathrm{mg}$ (o bien una dosis de $5 \mathrm{mg} / \mathrm{kg} /$ día durante 3 días mensualmente), junto con medidas protectoras personales como el empleo de insecticidas y repelentes (dimetilfalato), el uso de pantalones largos y la protección durante el sueño.

\section{BIBLIOGRAFÍA}

1. Carbonez G, Van De Sompel W, Zeyen T. Subconjunctival Loa Loa worm: case report. Bull Soc Belge Ophtalmol 2002; 283: 45-48.

2. Jolly BT, Foley KA. Loiasis: a case of an unusual ocular foreign body. Ann Emerg Med 1992; 21: 1153-1156.

3. Patel CK, Churchill D, Teimory M, Tabendeh H. Unexplained foreign body sensation: Thinking of loiasis in at risk patients prevents significant morbidity. Eye 1993; 7: 714-715.

4. Geldelman D, Blumberg R, Sadun A. Ocular Loa Loa with cryoprobe extraction of subconjuntival worm. Ophthalmology 1984; 91: 300-303.

5. Fobi G, Gardon J, Santiago M, Ngangue D, Gardon-Wendel $N$, Boussinesq M. Ocular findings after ivermectin treatment of patients with high Loa-loa microfilaremia. Ophthalmic Epidemiol 2000; 7: 27-39. 